\title{
Detection and distribution of anti-leptospiral antibody among dogs and their handlers
}

\author{
Goh, S.H. ${ }^{1}$, Khor, K.H. ${ }^{1}$, Ismail, R. ${ }^{2}$, Megat Abdul Rani, P.A. ${ }^{1}$, Mohd Mohidin, T.B. ${ }^{3}$, Bahaman, A.R. ${ }^{1}$, \\ Khairani-Bejo, S. ${ }^{1}$, Radzi, R. ${ }^{1}$, Alashraf, A.R. ${ }^{1}$, Sabri, A.R. ${ }^{1}$ and Lau, S.F. ${ }^{*}$ \\ ${ }^{1}$ Faculty of Veterinary Medicine, Universiti Putra Malaysia, 43400 Serdang Selangor, Malaysia \\ ${ }^{2}$ Faculty of Medicine, Universiti Kebangsaan Malaysia, 43600 UKM, Bangi Selangor, Malaysia \\ ${ }^{3}$ Faculty of Science, University of Malaya, 50603 Kuala Lumpur Malaysia \\ *Corresponding author e-mail: lausengfong@upm.edu.my \\ Received 15 April 2019; received in revised form 10 August 2020; accepted 11 August 2020
}

\begin{abstract}
The incidence of leptospirosis seems to be on the rise and could be an alarming indirect indication of a global re-emergence. It is a potential public health threat when dogs are speculated to be involved in the transmission of leptospirosis through possible subclinical harbouring of Leptospira spp. and subsequent shedding into the environment. This study aimed to detect anti-leptospiral antibodies among dogs and their handlers using the microscopic agglutination test (MAT). Blood samples from 266 apparently healthy dogs and 194 dog handlers were collected at four working dog organisations and four dog shelters. Serum samples were tested using MAT against 20 leptospiral serovars with a cut-off titre $\geq 1: 100$ (dog) and $\geq 1: 50$ (dog handlers). Seventy dogs $(70 / 266 ; 26.3 \%)$ were seropositive mainly against serovars Icterohaemorrhagiae, Ballum, Bataviae and Javanica (titres ranged: 1:100-1:800). Sixty-seven dog handlers (67/194; 34.5\%) were seropositive mainly against serovars Grippotyphosa, Icterohaemorrhagiae and Malaysia (titres ranged: 1:50-1:200). Dogs were seropositive due to exposure, vaccination or active infection. Seropositive dog handlers could indicate exposure or active infection. This shows the potential of dogs in maintaining and spreading the infection in Malaysia. Due to the occupational risk as a result of frequent contact with dogs and exposure to contaminated environments, dog handlers should be made aware of the presence of this zoonotic disease.
\end{abstract}

\section{INTRODUCTION}

Leptospirosis an emerging zoonotic disease caused by Leptospira spp. It occurs worldwide especially in tropical regions like Malaysia. Annually, 1.03 million cases were reported globally with mortality of $5.72 \%$ (Costa et al., 2015). In 2015, the Disease Control Division of the Ministry of Health Malaysia estimated that 30.2/100000 new cases were reported annually. Although incidence has increased within the decade, underestimation occurs as infections unrelated to flood were rarely reported. In Malaysia, reported human cases have always been associated with exposure to contaminated soil and water. Outbreaks occur with flooding during the monsoon season (Benacer et al., 2016).
Leptospira spp. is harboured by animal carriers, rats being the most common (Levett et al., 2009). Other animals like dogs have been speculated to play a vital role in transmission of infection. Recent canine seroprevalence data has shown a wide variation of detected serovars in dogs (Ambily et al., 2013; Habus et al., 2017). A few preliminary studies in Malaysia reported a seroprevalence of canine leptospirosis between 3.0 to $7.0 \%$ from shelter, pet and working dogs (Khor et al., 2016; Lau et al., 2016, 2017).

It is associated with a wide range of occupations such as sewage and oil palm plantation workers (Ridzuan et al., 2016). These studies speculated disease transmission either via direct contact with rats or indirectly from the contaminated 
environment. Leptospiral infection was reported in occupations involving animals contact such as slaughterhouse and dairy farm workers resulting from handling of infected live animals and carcasses (Dreyfus et al., 2015).

Infected dogs can be a potential public health threat to humans. In Malaysia, anecdotal evidence has been reported in newspapers of dog owners falling ill from contact with their infected dogs. Mostly dogs are kept as pets, except for the ones used for certain tasks like drug sniffing etc. Therefore, it could be an occupational risk for dog handlers (Awosanya et al., 2013). This study aimed to detect anti-leptospiral antibody in working and shelter dogs and their handlers. Serological surveillance provides much needed preliminary assessment of leptospirosis in managing its endemicity (MOH, 2015; Benacer et al., 2016).

\section{MATERIALS AND METHODS}

This cross-sectional study was carried out on dogs and their handlers from four working dog organisations and four dog shelters in the states of Johor, Kuala Lumpur, Negeri
Sembilan and Selangor. The working dog organisations were located in urban regions amongst commercial and residential areas. Dog shelters on the other hand were rurally located amidst forest regions and agricultural land. They were contacted and approval for participation was obtained. Research ethical approval was obtained from the Institutional Animal Care and Use Committee (UPM/ IACUC/AUP-R091/2016) which allowed for handling of dogs and Research Ethics Committee (UKMPPI/111/8/JEP-2016-494) allowing for recruitment of dog handlers. Information obtained was confidential and to be only used for research purposes.

\section{Demographics}

For the selected dogs, demographic information was retrieved from available records as shown in Table 1 . Social demographic information of the dog handlers obtained was as shown in Table 2.

\section{Blood Collection}

Blood samples were collected from the cephalic vein of dogs by a trained veterinarian. Meanwhile, human blood samples were collected from a brachial vein puncture by a licensed medical doctor. All the samples were immediately transported in chiller

Table 1. Demographics of selected dogs $(n=266)$

\begin{tabular}{llc}
\hline Items & & Frequency (\%) \\
\hline \multirow{2}{*}{ Dender } & Male & $187(70.3)$ \\
\cline { 2 - 3 } & Female & $79(29.7)$ \\
\hline Median Age (Range) & Shelter Dog & $193(72.6)$ \\
\cline { 2 - 3 } Vaccination Status & Working Dog & $73(27.4)$ \\
\hline Vaccine Type & Vaccinated & 3 years (1-11 years) \\
\cline { 2 - 3 } & Unvaccinated & $142(53.4)$ \\
\hline Breeds & Bivalent (Icterohaemorrhagiae \& Canicola) & $124(46.6)$ \\
\cline { 2 - 3 } & Quadrivalent (Icterohaemorrhagiae Canicola, & $39(27.5)$ \\
\hline & Grippotyphosa and Pomona) & $191(71.8)$ \\
\hline & Local & $36(13.5)$ \\
\cline { 2 - 3 } & Labrador & $18(6.8)$ \\
\cline { 2 - 3 } & German Shepherd Dog & $2(3.7)$ \\
\cline { 2 - 3 } & Malinois & $9(0.8)$ \\
\cline { 2 - 3 } & English Spriner Spaniel & $3.4)$ \\
\cline { 2 - 3 } & Cocker Spaniel & $103)$ \\
\hline
\end{tabular}


Table 2. Demographics of selected dog handlers $(\mathrm{n}=194)$

\begin{tabular}{lc}
\hline Items & Frequency (\%) \\
\hline Gender & $162(83.5)$ \\
Male & $32(16.5)$ \\
Female & \\
\hline Race / Nationality & $15(7.7)$ \\
Malay & $55(28.4)$ \\
Indian & $43(22.2)$ \\
Chinese & $54(27.8)$ \\
Borneo Indigenous & $13(6.7)$ \\
Indonesian & $13(6.7)$ \\
Myanmarese & $1(0.5)$ \\
Pakistani & \\
\hline Handler Type & $70(36.1)$ \\
Shelter Dog Handlers & $124(63.9)$ \\
Working Dog Handlers & \\
\hline Median Age (Range) & 37 years $(20-61$ years) \\
\hline Job Description & $55(28.4)$ \\
Administration & $28(14.4)$ \\
Kennel man & $77(39.7)$ \\
Dog Handler & $34(17.5)$ \\
Volunteers & \\
\hline
\end{tabular}

boxes at $4^{\circ} \mathrm{C}$ to the Bacteriology Laboratory in the Faculty of Veterinary Medicine, University Putra Malaysia. Samples were centrifuged at $5000 \mathrm{rpm}$ for 10 minutes. The serum obtained was aliquoted into $1.5 \mathrm{~mL}$ Eppendorf ${ }^{\circledR}$ Microcentrifuge tubes and stored at $-20^{\circ} \mathrm{C}$ for further analysis.

\section{Microscopic Agglutination Test (MAT)}

MAT was performed according to procedure described by the World Organisation for Animal Health (OIE). All samples were tested against 20 leptospiral serovars antigens, based on the common pathogenic serovars found in dogs/humans or both, including an environmental pathogenic serovar and a saprophytic serovar to determine the level of agglutinating antibodies (Slack et al., 2009; Lim, 2011; Khor et al., 2016; Lau et $a l ., 2016)$ as shown in Table 3. All antigens were obtained from Leptospirosis Reference Laboratory, Queensland Health, Queensland, Australia. The sample was considered seropositive if there was $<50 \%$ free leptospires

Table 3. Leptospiral antigen panel for microscopic agglutination test (MAT)

\begin{tabular}{|c|c|c|}
\hline Species & Serovar & Strain \\
\hline \multirow[t]{12}{*}{ L. interrogans } & Icterohaemorrhagiae & RGA \\
\hline & Canicola & Hond Utrecht IV \\
\hline & Pomona & Pomona \\
\hline & Bataviae & Swart \\
\hline & Australis & Ballico \\
\hline & Tarassovi & Perepelitsin \\
\hline & Autumnalis & Akiyami A \\
\hline & Pyrogenes & Salinem \\
\hline & Hebdomadis & Hebdomadis \\
\hline & Hardjo & Hardjoprajitno \\
\hline & Lai & Lai \\
\hline & Copenhageni & Fiocruz \\
\hline L. weilii & Celledoni & Celledoni \\
\hline \multirow[t]{2}{*}{ L. kirschneri } & Grippotyphosa & Moskva V \\
\hline & Cynopteri & $3522 \mathrm{C}$ \\
\hline \multirow[t]{3}{*}{ L. borgpetersenii } & Ballum & Mus 127 \\
\hline & Hardjobovis & 117123 \\
\hline & Javanica & Veldrat Bataviae 46 \\
\hline L. kmetyi & Malaysia & Bejo-Iso $9^{\mathrm{T}}$ \\
\hline L. biflexa & Patoc & Patoc 1 \\
\hline
\end{tabular}


and $>50 \%$ agglutination when compared to the positive control (hyperimmune serum) and negative control (antigen only). Cut off titre of 1:100 (dogs) (OIE, 2014) and 1:50 (dog handlers) were used in this study. The suspected infecting serovar was determined based on the serovar with the highest titre.

\section{Statistical Analysis}

All the data was tabulated and analysed descriptively using IBM ${ }^{\circledR}$ SPSS ${ }^{\circledR}$ Statistics Version 23. Data was presented as frequency and percentages of seropositivity.

\section{RESULTS}

\section{Microscopic Agglutination Test (MAT)}

The seroprevalence among dogs was $26.3 \%$ ( $\mathrm{n}=70 / 266)$ (titres ranged: 1:100-1:800). The seropositive levels from dog shelters and working dog organisations are shown in Figure 1. The percentage of seropositive sheltered dogs was higher $(19.9 \% ; n=53 / 266)$ as compared to working dogs (6.4\%; $\mathrm{n}=17$ / $266)$. From the 70 seropositive dogs, 44 dogs $(62.8 \%)$ were vaccinated. These $44 \mathrm{dogs}$ comprised of 16 working dogs and 28 shelter dogs. Out of 142 vaccinated dogs, $30.9 \%(n=44)$ were seropositive. Each of two working dog organisations (W3 and W4) had one seropositive dog. The distribution of leptospiral serovars, detected among dogs is shown in Table 4. Thirteen leptospiral serovars were detected with the prominent ones as follows; Icterohaemorrhagie (9\%), Ballum (5.3\%), Bataviae (3.4\%), and Javanica (2.6\%). The common serovars among nonvaccinated dogs were Ballum (3.8\%) and Icterohaemorrhagiae (2.6\%) whereas in the vaccinated dogs Icterohaemorrhagiae (6.4\%) and Bataviae (2.6\%) were prominent.

The seroprevalence among dog handlers was $34.5 \%(\mathrm{n}=67 / 194)$ (Figure 1) (titres ranged: 1:50-1:200). Forty-six (68.7\%) of the 67 seropositive dog handlers worked at the dog shelters while the remaining 21 (31.3\%) were from the working dog organisations. Two working dog organisations had seropositive dog handlers; W1 at 6.2\% $(\mathrm{n}=12 / 194)$ and $\mathrm{W} 2$ at $4.6 \%(\mathrm{n}=9 / 194)$. The highest serodetection level among the dog handlers was from dog shelter S4 at 17.5\% $(\mathrm{n}=34 / 194)$ whereas the lowest was from dog shelter S3 at 1.6\% $(n=3 / 194)$. Dog handlers were seropositive for 11 serovars, with the main ones being Grippotyphosa (7.73\%), Malaysia (6.19\%) and Icterohaemorrhagiae (5.15\%) as shown in Table 4.

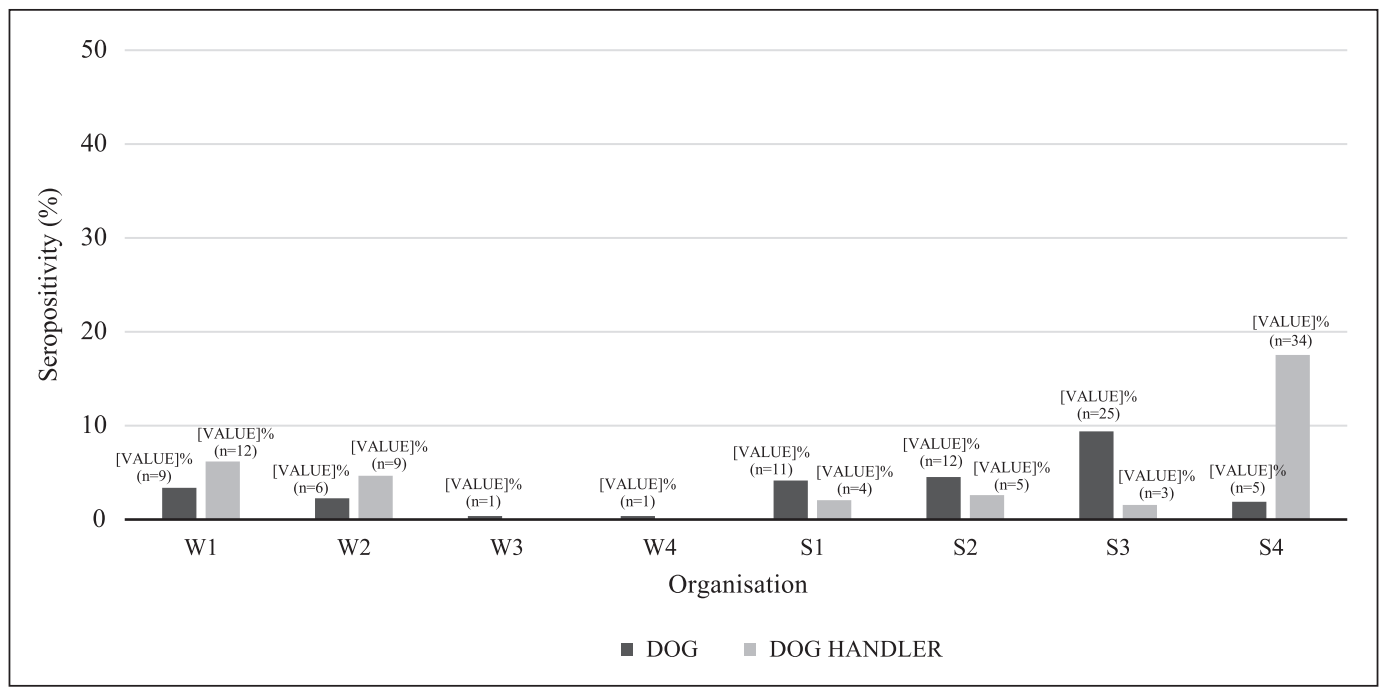

Figure 1. Seropositivity distribution by organisation among dogs ( $=266)$ and dog handlers $(\mathrm{N}=194)$ ( $\mathrm{w}=$ working and $\mathrm{s}=$ shelters). 
Table 4. Distribution of leptospiral serovars among dogs and dog handlers

\begin{tabular}{|c|c|c|c|c|c|c|}
\hline \multirow{2}{*}{ Serovars } & \multicolumn{2}{|c|}{$\operatorname{Dog}(1: 100)$} & \multirow{2}{*}{ n (\%) } & \multicolumn{2}{|c|}{ Dog Handler (1:50) } & \multirow{2}{*}{$\mathrm{n}(\%)$} \\
\hline & Working & Shelter & & Working & Shelter & \\
\hline Icterohaemorrhagiae & 11 & 13 & $24(9.0)$ & 3 & 7 & $10(5.2)$ \\
\hline Canicola & - & 1 & $1(0.4)$ & 1 & 1 & $2(1.0)$ \\
\hline Grippotyphosa & 1 & 1 & $2(0.8)$ & 5 & 10 & $15(7.7)$ \\
\hline Australis & 1 & 2 & $3(1.1)$ & 3 & - & $3(1.6)$ \\
\hline Autumnalis & - & 1 & $1(0.4)$ & - & - & - \\
\hline Lai & - & 5 & $5(1.9)$ & - & - & - \\
\hline Ballum & - & 14 & $14(5.3)$ & - & - & - \\
\hline Hardjobovis & 1 & - & $1(0.4)$ & - & - & - \\
\hline Hardjo & - & 1 & $1(0.4)$ & 0 & 4 & $4(2.1)$ \\
\hline Bataviae & 1 & 8 & $9(3.4)$ & 0 & 4 & $4(2.1)$ \\
\hline Javanica & - & 7 & $7(2.6)$ & - & - & - \\
\hline Pyrogenes & 1 & - & $1(0.4)$ & 5 & 1 & $6(3.1)$ \\
\hline Hebdomadis & - & - & - & - & 5 & $5(2.6)$ \\
\hline Patoc & - & - & - & 3 & 2 & $5(2.6)$ \\
\hline Malaysia & - & - & - & - & 12 & $12(6.2)$ \\
\hline Cynopteri & - & - & - & 1 & - & $1(0.5)$ \\
\hline Copenhageni & 1 & - & $1(0.4)$ & - & - & - \\
\hline Total & 17 & 53 & $70(26.3)$ & 21 & 46 & $67(34.5)$ \\
\hline
\end{tabular}

\section{DISCUSSION}

The involvement of dogs in leptospirosis transmission among animals and humans has longed been speculated. Their role varies depending on interaction with the Leptospira spp. excreted by animal reservoirs or indirectly through contaminated water and soil (Adler et al., 2010). Aside from being pets, dogs were trained for tasks such as herding livestock, aiding the disable, hunting etc (Mariti et al., 2013). This will potentially expose them to the pathogen. Immunological assessment provides vital information regarding its local presence.

In our study, dog shelters $(19.9 \%, \mathrm{n}=53 /$ 266) had more seropositive dogs compared to working dog organisations (6.4\%, $\mathrm{n}=17$ / 266). It is higher than previous local studies of 3.8\% (n=3/80) (Khor et al., 2016) and 7.0\% ( $n=4 / 57)$ (Lau et al., 2016), as fewer shelters were previously recruited. Similar results had also been reported among shelter dogs in Brazil (20.0\%) (de Paula Dreer et al., 2013).
Shelter management plays an important role in the transmission of leptospirosis. The dirty and poorly managed shelters in this study eased disease transmission. More seropositive dogs $(6.4 \%, \mathrm{n}=17 / 266)$ were found in the working dog organisations as compared to reports by Lau (3.1\%) (Lau et $a l ., 2017)$. It is attributed to a larger sample size incorporating working dog organisations with diverse working environment and risk.

Three main serovars detected among dogs were Icterohaemorrhagie, Ballum and Bataviae. The absence of Ballum and Bataviae in commercial vaccines suggests potential exposure. These serovars were similar to reports in different groups of dogs i.e. stray dogs, shelter dogs and also pet dogs in countries such as Serbia, Colombia, India, Mexico, and Croatia (Majetić et al., 2012; Ambily et al., 2013; Cruz-romero et al., 2013; Vojinoviæ et al., 2015). Among working dogs, the detection of serovar Icterohaemorrhagiae, Grippotyphosa, Australis, Hardjobovis, Bataviae, 
Pyrogenes, and Copenhageni was consistent with previous reports with the addition of serovar Javanica (Lau et al., 2017). Having been tasked at various locations (exposures) resulted in such diversity. Detection of Icterohaemorrhagiae and Grippotyphosa could likely be from vaccination with the remaining serovars be due to past exposure.

The most common serovar among shelter dogs was Ballum. Our findings differed from studies in Brazil (de Paula Dreer et $a l ., 2013$ ) where Copenhageni was the most prevalent. Local studies on dog shelters detected other serovars such as Icterohaemorrhagie and Canicola (Lau et al., 2016) and Bataviae (3.8\%, n=3/80) (Khor et $a l ., 2016)$. Differences in shelter environment lead to such variation. Different geographical areas and the presence of different species of reservoir animals may also affect the serovars detected (Pui et al., 2017). This possibility was not able to be investigated.

Dog shelters were in rural areas amongst agricultural land and forest regions, allowing domestic and wild animals to encroach on the grounds of the shelter. All dog shelters had environments conducive for attracting reservoir animals. With a high number of dogs in the shelters, each enclosed cage housed many dogs and had large centralised trays providing ad libitum food and waters. This would attract reservoir animals into the feeding area. Disease management is challenging due to limited space as sick and healthy dogs are housed together further spreading the disease. Dogs are allowed to roam freely within the shelter. The working dog organisations institutions were better managed with good hygiene practices and clean enclosed areas for their dogs. As an integral part of these government agencies, the dogs are provided protection through immunisation. The diversity in leptospiral serovars causes limitations, as protection is serovar specific. The shelter dogs were not provided similar immunisation making them more susceptible.

MAT provided information on the presence of antibodies towards specific serovars that affects the dogs and dog handlers from these selected locations.
Detection warrants further investigation into the source of infection in both humans and dogs. Antibody titres of more than 1:100 among occult healthy dogs in the current study may suggest possible infection or carrier status. However, the true status (active infection, exposure or vaccination) remains unknown as molecular detection was not carried out. Urine samples are crucial to prove the potential of dogs as an infection source spreading the disease to animals and humans working closely with them.

More dog shelter handlers were seropositive similar to reports by Awosanya among kennel workers where $66 \%(n=10 / 15)$ were positive. This could be caused by similar unhygienic working environments. Poor hygiene practices among kennel workers in a dirtier environment potentiates risk of infection. Slaughterhouse workers from Kenya and New Zealand were at higher risk from direct contact with infected animals and offal with serodetection of $13.4 \%$ (Cook et $a l ., 2017$ ) and 8.3\% (Dreyfus et al., 2015) respectively. In Malaysia, human vaccination is not practiced, thus seropositive cases among healthy dog handlers using low cutoff titre of 1:50 would suggest exposure possibly from frequent contact with the dogs or working in contaminated environments during various operations.

In Malaysia, past studies had looked at leptospirosis among various occupations. A survey on town service workers documented a seroprevalence of $24.7 \%$ (Shafei et al., 2012). Ridzuan reported that $28.6 \%$ of oil palm plantation workers were seropositive (Ridzuan et al., 2016). Another study by Rafizah among febrile hospital patients found a seroprevalence of $8.4 \%$ with agricultural workers being the most common (Rafizah et al., 2013). These results indicate that individuals working in possibly contaminated environment such as plantations and garbage collection area are at risk of infection due to presence of reservoir animals. Serovars Grippotyphosa and Malaysia have not been vastly reported locally. Local studies reported serovars Sejroe (Rafizah et al., 2013), Patoc 1 (Shafei et al., 2012) and Sarawak (Ridzuan et al., 
2016). Grippotyphosa can normally be found in raccoons, marsupials and sometimes cattle (Mgode et al., 2015). Malaysia is an environmental pathogenic serovar thus indicating possible environmental exposure (Slack et al., 2009). Similarity in serovars among dog handlers and dogs could be exposure to the same source of infection or potential transmission from dogs to humans. Unfortunately, the source of exposure could not be determined.

The conclusion that could be drawn was that different groups were observed to have different exposures from different working environments. Tasks such as search and rescue, cadaver retrieval, fugitive apprehension, narcotic detection, bomb detection, and contraband detection, exposes working dogs and their handlers to various sources of infection. Despite having diverse working environment, serodetection is lower among working dog handlers possibly due to the high level of protection from protective uniforms and gear during their operations mitigating the risk of infection by prevent injuries and reducing environmental exposure to leptospires (Thibeaux et al., 2017). Infections among dog shelters handlers occur from working in humid unhygienic conditions with the presence of leptospires excreting reservoirs animals (rats) allowing environmental persistence (Senthil et al., 2013). Limited formal education among foreigners lead to a lack of PPE awareness and usage which increases the risk of infection (Awosanya et al., 2013). Their exposure was further prolonged from staying within the dog shelters itself. Unlike the working dog organisations with government funding, the limited funding of dog shelters causes operational limitations such as proper disease control and preventive measures through vaccination and veterinary care.

Canine immunisation has been vastly implemented worldwide using either a quadrivalent (Icterohaemorrhagiae, Canicola, Grippotyphosa and Pomona) or a bivalent (Icterohaemorrhagiae and Canicola) vaccine (Day et al., 2016). This resulted in a decrease in canine leptospirosis caused by vaccine serovars as seen in the United States and
Canada (Lee et al., 2014). Despite vaccination efforts, cases are still reported in recent years with newer serovars (Roqueplo et $a l ., 2014$; Delaude et al., 2017). Initiatives to incorporate them into commercial vaccines is ongoing. In this study, detection of Ballum, Bataviae and Javanica puts these dogs at risk of getting infected with their absence in commercial vaccine. Continuous local work is warranted in efforts to reveal the role of dogs in the disease dissemination.

\section{CONCLUSION}

This study investigated the serological detection of anti-leptospiral antibodies in both dogs and dog handlers. Rats in both organisational types were believed to be the infection source. There was the possibility of the dogs disseminating the disease amongst themselves and to their handlers posing a public health threat with the risk of potential outbreaks. Confirmatory tests are warranted to determine role of dogs in disease transmission between animals and humans. Urine and whole blood samples for isolation and molecular detection should be included to prove the presence of the organism. Effective preventative and control protocols for leptospirosis should be implemented for both dogs and handlers especially for those in dog shelters to reduce the public health impact.

Acknowledgements. The authors would like to acknowledge the contributions of all who were involved. We are also grateful to the shelters and working dog institutions for their willingness to participate in the study. The authors would also like to thank the staff from the Bacteriology Laboratory of the Faculty of Veterinary Medicine, Universiti Putra Malaysia, for their assistance in processing the samples and technical help. Our appreciation also goes to MyOHUN for funding this research under the MyOHUN Seed Fund Award 2016.

\section{Conflict of interest}

All authors report no conflict of interest relevant to this article. 


\section{REFERENCES}

Adler, B. \& de la Pena Moctezuma, A. (2010). Leptospira and leptospirosis. Veterinary Microbiology 140: 287-296.

Ambily, R., Mini, M., Joseph, S., Krishna, S.V. \& Abhinay, G. (2013). Canine leptospirosis - a seroprevalence study from Kerala, India. Veterinary World 6(1): 42-44.

Awosanya, E.J., Nguku, P., Oyemakinde, A. \& Omobowale, O. (2013). Factors associated with probable cluster of Leptospirosis among kennel workers in Abuja, Nigeria. Pan African Medical Journal 16: 1-6.

Benacer, D., Kwai, L.T., Ng, C.M., Verasahib, K., Bin, Galloway, R.L., Hartskeerl, R.A., Souris, M. \& Mohd Zain, S.N. (2016). Epidemiology of human leptospirosis in Malaysia, 2004-2012. Acta Tropica 157: 162-168.

Cook, E.A.J., De Glanville, W.A., Thomas, L.F., Kariuki, S., Bronsvoort, B.M.D.C. \& Fèvre, E.M. (2017). Risk factors for leptospirosis seropositivity in slaughterhouse workers in western Kenya. Occupational and Environmental Medicine 74(5): 357-365.

Costa, F., Hagan, J.E., Calcagno, J., Kane, M., Torgerson, P., Martinez-Silveira, M.S., Stein, C., Abela-Ridder, B. \& Ko, A.I. (2015). Global Morbidity and Mortality of Leptospirosis: A Systematic Review. PLoS Neglected Tropical Diseases 9(9): $0-1$.

Cruz-romero, A., Romero-salas, D., Aguirre, C.A., Aguilar-, M. \& Bautista-piña, C. (2013). Frequency of canine leptospirosis in dog shelters in Veracruz, Mexico. African Journal of Microbiology Research 7(16): 1518-1521.

Day, M.J., Horzinek, M.C., Schultz, R.D. \& Squires, R.A. (2016). WSAVA Guidelines for the vaccination of dogs and cats. Journal of Small Animal Practice 57(1): E1-E45.

de Paula Dreer, M.K., Gonçalves, D.D., da Silva Caetano, I.C., Gerônimo, E., Menegas, P.H., Bergo, D., Ruiz LopesMori, F.M., Benitez, A., de Freitas, J.C., Evers, F., Navarro, I.T. \& de Almeida
Martins, L. (2013). Toxoplasmosis, leptospirosis and brucellosis in stray dogs housed at the shelter in Umuarama municipality, Paraná, Brazil. Journal of Venomous Animals and Toxins Including Tropical Diseases 19(1): 23.

Delaude, A., Rodriguez-Campos, S., Dreyfus, A., Counotte, M.J., Francey, T., Schweighauser, A., Lettry, S. \& Schuller, S. (2017). Canine leptospirosis in Switzerland - A prospective crosssectional study examining seroprevalence, risk factors and urinary shedding of pathogenic leptospires. Preventive Veterinary Medicine 141: 48-60.

Dreyfus, A., Wilson, P., Collins-Emerson, J., Benschop, J., Moore, S. \& Heuer, C. (2015). Risk factors for new infection with Leptospira in meat workers in New Zealand. Occupational and Environmental Medicine 72(3): 219-225.

Habus, J., Persic, Z., Spicic, S., Vince, S., Stritof, Z., Milas, Z., Cvetnic, Z., Perharic, M. \& Turk, N. (2017). New trends in human and animal leptospirosis in Croatia, 2009-2014. Acta Tropica 168: 1-8.

Khor, K.H., Tan, W.X., Lau, S.F., Mohd, A.R., Rozanaliza, R., Siti, K.B. \& Abdul, R.B. (2016). Seroprevalence and molecular detection of leptospirosis from a dog shelter. Tropical Biomedicine 33(2): 276-284.

Lau, S.F., Low, K.N., Khor, K.H., Roslan, M.A., Bejo, S.K., Radzi, R. \& Bahaman, A.R. (2016). Prevalence of leptospirosis in healthy dogs and dogs with kidney disease in kidney disease in Klang Valley, Malaysia. Tropical Biomedicine 33(3): 469-475.

Lau, S.F., Wong, J.Y., Khor, K.H., Roslan, M.A., Abdul Rahman, M.S., Bejo, S.K., Radzi, R. \& Bahaman, A.R. (2017). Seroprevalence of Leptospirosis in Working Dogs. Topics in Companion Animal Medicine 32(4): 121-125.

Lee, H.S., Guptill, L., Johnson, A.J. \& Moore, G.E. (2014). Signalment changes in canine leptospirosis between 1970 and 2009. Journal of Veterinary Internal Medicine 28(2): 294-299. 
Levett, P.N. \& Edwards, C.N. (2009). Leptospirosis. Bacterial Infections of Humans. Boston, MA, USA. Springer US.

Lim, V. (2011). Leptospirosis: A re-emerging infection. The Malaysian Journal of Pathology 33(1): 1-5.

Majetić, Z.S., Habuš, J., Milas, Z., Perko, V.M., Starešina, V. \& Turk, N. (2012). Serological survey of canine leptospirosis in Croatia - The changing epizootiology of the disease. Veterinarski Arhiv 82(2): 183191.

Mariti, C., Ricci, E., Carlone, B., Moore, J.L., Sighieri, C. \& Gazzano, A. (2013). Dog attachment to man: A comparison between pet and working dogs. Journal of Veterinary Behavior 8(3): 135-145.

Mgode, G.F., Machang'u, R.S., Mhamphi, G.G., Katakweba, A., Mulungu, L.S., Durnez, L., Leirs, H., Hartskeerl, R.A. \& Belmain, S.R. (2015). Leptospira Serovars for Diagnosis of Leptospirosis in Humans and Animals in Africa: Common Leptospira Isolates and Reservoir Hosts. PLoS Neglected Tropical Diseases 9(12): 1-19.

$\mathrm{MOH}$. (2015). Epidemiology and Current Situation of Leptospirosis in Malaysia. Dr. Zainudin AW Persidangan Kesihatan Persekitaran Pihak Berkuasa Tempatan 2015 8-9 September 2015, WP Labuan, (Persidangan Kesihatan Persekitaran Pihak Berkuasa Tempatan 2015 8-9 September 2015, WP Labuan.).

OIE. (2014). Leptospirosis. Manual of Diagnostic Tests and Vaccines for Terrestrial Animals. Pp. 1-15. OIE, Paris. Pui, C.F., Bilung, L.M., Apun, K. \& Su'ut, L. (2017). Diversity of Leptospira spp. in Rats and Environment from Urban Areas of Sarawak, Malaysia. Journal of Tropical Medicine 2017: 1-8.

Rafizah, A.A.N., Aziah, B.D., Azwany, Y.N., Imran, M.K., Rusli, A.M., Nazri, S.M., Nikman, A.M., Nabilah, I., Asma', H.S., Zahiruddin, W.M. \& Zaliha, I. (2013). A hospital-based study on seroprevalence of leptospirosis among febrile cases in northeastern Malaysia. International Journal of Infectious Diseases 17(6): e394-e397.
Ridzuan, J.M., Aziah, D. \& Zahiruddin, W.M. (2016). Study on Seroprevalence and Leptospiral Antibody Distribution among High-risk Planters in Malaysia. Osong Public Health and Research Perspectives 7(3): 168-171.

Roqueplo, C., Marié, J., André-fontaine, G., Kodjo, A. \& Davoust, B. (2014). Serological survey of canine leptospirosis in three countries of tropical Africa: Sudan, Gabon and Ivory Coast. Comparative Immunology, Microbiology and Infectious Diseases 38: 57-61.

Senthil, N.R., Palanivel, K.M. \& Rishikesavan, R. (2013). Seroprevalence of Leptospiral Antibodies in Canine Population in and around Namakkal. Journal of Veterinary Medicine 2013: 1-4.

Shafei, M.N., Sulong, M.R., Yaacob, N.A., Hassan, H., Wan Mohamad, W.M.Z., Daud, A., Ismail, Z. \& Abdullah, M.R. (2012). Seroprevalence of Leptospirosis among Town Service Workers in Northeastern State of Malaysia. Intermational Journal of Collaborative Research on Internal Medicine \& Public Health 4(4): 395-403.

Slack, A.T., Khairani-Bejo, S., Symonds, M.L., Dohnt, M.F., Galloway, R.L., Steigerwalt, A.G., Bahaman, A.R., Craig, S., Harrower, B.J. \& Smythe, L.D. (2009). Leptospira kmetyi sp. nov., isolated from an environmental source in Malaysia. International Journal of Systematic and Evolutionary Microbiology 59(4): 705-708.

Thibeaux, R., Geroult, S., Benezech, C., Chabaud, S., Soupé-Gilbert, M.E., Girault, D., Bierque, E. \& Goarant, C. (2017). Seeking the environmental source of Leptospirosis reveals durable bacterial viability in river soils. PLoS Neglected Tropical Diseases 11(2): 1-14.

Vojinović, D., Bogićević, N., Vasić, A., Manić, M., Elezović Radovanović, M., Rogožarski, D., Marić, J. \& Valèić, M. (2015). Seroepidemiological survey of leptospiral infection in stray dogs in Serbia. Turkish Journal of Veterinary and Animal Sciences 39(6): 719-723. 